\title{
A Spreadsheet-Based Approach for Operations Research Teaching
}

\author{
Susila Munisamy \\ Faculty of Economics and Administration, University of Malaya \\ 50603 Kuala Lumpur, Malaysia \\ E-mail: susila@um.edu.my
}

\begin{abstract}
This paper considers the use of spreadsheet for introducing students to a variety of quantitative models covered in an introductory Operations Research (OR) course at the University of Malaya, Malaysia. This approach allows students to develop skills in modeling as they learn to apply the various quantitative models in a spreadsheet. Indeed, imparting spreadsheet and modeling skills with OR skills will make students highly sought after in the modern workplace. This paper goes on to report on the experience in using spreadsheet in the Introductory OR course and students evaluations.
\end{abstract}

Keywords: Spreadsheet, Operations Research, University education

\section{Introduction}

The primary emphasis of a typical Operations Research (OR) course in the mid-to-late 1980s was on the theory and algebra of various solution algorithms, while the primary format was the traditional lectures. Modeling and empirical work i.e. real world problem solving received little attention. While the traditional lecture imparts factual knowledge, it did not develop the basic modeling skills of students, which will enable them to apply OR in the real-world. Cochran (2000) wrote that many students who had taken a traditional OR course complained that OR was not relevant and found that at the end of the course students were unable to recognize when application of the various operations research models was appropriate, how to formulate all but the simplest problems, or how to properly interpret the results of their analyses.

Using the spreadsheet approach in teaching OR has been strongly recommended as one of the ways to develop students modeling skills (Powell 1997a, 1998; Savage, 1997; Thiriez, 2001). The use of spreadsheet in OR teaching has gained general acceptance. There is evidence of movement in this direction. More OR text-books are being produced that address this approach to teaching. These books allow adopters to go beyond teaching theory and algorithms and provide students with practice of modeling management problems (for example, Managerial Decision Modeling with Spreadsheet, Balakrishnan et al., 2007). There are workshops on teaching OR using spreadsheet that share and debate teaching innovations around spreadsheet, where instructors have the opportunity to refresh their teaching skills (for example, INFORMS Annual Teaching of Management Science Workshop). Many articles on spreadsheet are written in high-visibility publications such as MS/OR Today and Interfaces (for example, Grossman 2003, 2006; Larry and Thomas, 2008; and Hesse and Scerno, 2009). Students are also demanding modeling and spreadsheet skills because they know that they need these practical skills to succeed in their jobs.

The next section provides the background of the introductory operations research course taught at the Faculty of Economics and Administration, University Malaya, Malaysia. The following section summarizes the aim of the OR course, its' underlying philosophy; how spreadsheet fits into that philosophy and the implications of using spreadsheet on the course design. This is followed by a section on the teaching approach taken to facilitate and enhance learning. The last section reviews the authors' experiences and students reactions to using spreadsheet in the introductory OR course. It also reflects on the design and planning of the introductory OR course using student evaluation measures.

\section{Background}

Introduction to Operations Research is a second-year undergraduate level elective course offered in the Faculty of Economics and Administration, University of Malaya. This course is offered through the Department of Applied Statistics and the author was assigned to teach the course for the first year. The students enrolled have economics background. A total of 52 students enrolled for this course in the 2004/05 session. Most of the students have taken no other OR courses, and the only common quantitative background they possess is a quantitative analysis course and a statistics course taken during the first year of the undergraduate programme. Initially their spreadsheet abilities vary greatly. Some students have already taken a course in spreadsheet and had some basic spreadsheet skills such as graphing and copying cells (but not model building); others had little or no experience of Excel.

Common topics included in the course are linear programming, PERT/CPM, inventory control, decision making, queueing theory and simulation. The course does not cover topics on regression, time series and forecasting because 
they are covered in other courses in the area of statistics delivered by the department. The topics were selected because they are most frequently used in practice (Thomas and DaCosta, 1979; Fortuin and Zijlstra, 2000). Each topic addresses the theoretical underpinning of the models covered. The emphasis is on understanding key concepts rather than detail of a specific algorithm. The author decided to try a spreadsheet based approach. Thus, the course views the OR topics through the lens of Microsoft Excel. The course meets three times in a week for one hour each in a computer classroom. The computer classroom has an instructor's PC and 30 students PCs. Hence, the students have to pair up and share a computer.

\section{A View of the OR Methodology and the Underlying Philosophy of the Course}

The aim of the course is to expose the students to the OR methodology and techniques, and to provide students with an understanding of its role in decision-making and problem solving. The phases of OR methodology are summarized in Figure 1. It is viewed as a three-phase process, covering problem formulation, model development and implementation. Each of the phase consists of several steps focusing on particular aspects of the phase, and the various phases are connected by feedback loops, and the process is iterative in the sense that the analyst may backtrack and go back to earlier steps (Winston and Albright, 2001). The second stage of the methodology is considered to be the most important because this is where the students learn model building and using them. If the groundwork is laid here then the students will be able to apply their skills to find practical solutions to real-life problems. The second stage deserves a different approach than traditional OR courses offers. Traditional OR courses have focused primarily on models. Models are the approaches and methodologies, such as those of linear programming or queueing theory, that present ready-made models by which situations may be analysed (Morris, 1967). Morris (1967) wrote that "the teaching of modeling is not the same as the teaching of models". Rather than the details of individual ready-made models, the students should be provided with an understanding of the logic associated with model development. They must be taught how to think about OR problems. Models are no substitute for thought and deliberation (Pidd, 1999). By learning the essentials of modeling, students can then create their own models and solve new problems that are different from the ones they have seen. Then the properly educated student can use the modeling skills to improve their own decision making and that of their organizations. Thus, I like Pidd (1999) and Powell (1997b), consider the real technical heart of OR to be modeling. When I refer to modeling, I am referring to the fundamental activity of explicitly creating a simplified representation of reality in order to understand reality better and to change, manage and control it in some way or another.

Spreadsheet such as Excel supports the development of modeling skills. They allow the instructor to teach students to be active modelers, besides helping the instructor to make concepts more concrete. Recently, some OR instructors have begun using spreadsheet as the primary modeling vehicle for teaching the concepts and tools in an OR course. In fact, many regard the spreadsheet as an excellent teaching tool for modeling (see for example, Powell 1997a; Powell, 1998; Savage, 1997; Thiriez, 2001 and Balakrishnan et al., 2007). Savage (1977) has discussed the pros and cons of using spreadsheet modeling. He stated that a compelling reason for using spreadsheet is the fact that there are "thirty million spreadsheet users" and that "spreadsheet has overwhelmingly become the analytical vernacular". Today there are many products and spreadsheet add-ins for mathematical optimization, stochastic simulation and decision analysis, such as Solver, Crystal Ball, Tree Plan and others. These allows OR models to be put on spreadsheet and, thereby, facilitate the application of OR.

Also, I believe that the aim of OR is not primarily to find optimal solutions, but to provide insights for informed decision making. An optimal solution is optimal only with respect to the specific model being used to represent the real problem and the model parameters used. Such a solution becomes a reliable guide for action only after it has been verified as performing well for other reasonable representation of the problem and when the potential consequence of changes in model parameters are recognized. This gives increased emphasis to sensitivity and error analysis. The spreadsheet has the ability to support sensitivity analysis or "what if" analysis of all kinds (Vazsonyi, 1993; Bodily, 1986; Leon et al., 1996). The effects of any number of assumptions on costs, revenues, profits and resource availability can be calculated quickly. This enables the solution to be analysed from a decision makers' perspective. Also, the interpretation of the results of using spreadsheet is important and this should be given emphasis.

The design of the OR course was firmly based on these considerations. The emphasize was on spreadsheet modeling; to focus on model building and analysis of results, rather than the model types themselves, and to use active-learning methods in which the students are empowered to identify, model, analyse and solve problems themselves rather than passive model consuming.

\section{The Teaching Approach}

The teaching approach reflects five principles: first, it is led by OR examples; second, there is a stepwise progression of skills; thirdly, active learning is used; fourthly, a structured methodology is discussed along with technique and examples; and fifthly, user-friendly design is encouraged. The discussion of each of these follows. 


\subsection{Example-driven}

Consistent with the philosophy of decision making and problem solving as an integral component of operations research, the course is taught using numerous realistic examples, many based on actual real-world problems (with modified data for illustrative purposes). The OR concepts and techniques, and the spreadsheet modeling concepts are illustrated with examples to provide a more meaningful and easier learning experience. Small problems are used to facilitate the learning process. This also allows solving by hand first before the spreadsheet solution is demonstrated. The examples are explained in a logical step-by-step fashion to guide the students, so that the students can subsequently emulate them in the homework problems. The actual computer output generated in solving the example problem is used to discuss the economic interpretation of the solution. The examples used are OR orientated and are across the curriculum: finance, marketing, operations, economics, and accounting. These examples show the variety of problems to which OR can be applied. They also demonstrate the relevance of OR in the real world and to other courses in the curriculum. Using real-world problems and using examples that relate to topics that the students have seen (or will see) elsewhere in the curriculum is considered to be one of the keys to the success of operations research (Winston, 1996; Powell, 1998).

\subsection{Stepwise progression}

The student modeler needs to acquire modeling skills that will be used in building and analysing any models, from the simplest to the most complex. Using spreadsheets such as Excel requires training in both the software and in modeling alongside the underlying OR techniques. The course does the training in progression. First, the students are introduced to the electronic spreadsheet and Excel. They are taught basic spreadsheet skills, such as the roles of label, value and formulae; how to use simple formulae; how to use various Excel functions, how to structure in blocks and copy formulae; how to distinguish between absolute and relative reference and how to create charts. At the next level, they are taught the basics of spreadsheet modeling, such as how to design a good spreadsheet (discussed in Section 4.4 below); how to create data tables and lookup tables, how to categorize variables, how to isolate parameters and how to establish a base case. The advanced level covers the use of Goal Seek and Solver; efficient sensitivity analysis; generation of random numbers; simulation; pattern analysis and the use of add-ins. These skills are all necessary in all modeling activities and the students learn these spreadsheet skills by following along with class examples, working on homework problems and course assessments.

\subsection{Active-learning}

The course was designed to allow students to take an active role in learning. This style of teaching replaces lectures with activities in which students do real work under the eyes of the instructor. The lecture is brief and one or two breaks is provided during which students undertake modeling tasks with the computer on problems related to the lecture. Additional problem sets are given for students to work on during class or as homework assignments. The students present their models and analysis in the class or during the discussion-based tutorials. In these activities, the students are building and analyzing models, rather than just listening to the lecture and watching the instructor doing them. By learning by doing, the students are being trained to be active modelers - the new paradigm of OR proposed by Powell (1997b).

\subsection{Structured methodology}

The course places emphasis on good spreadsheet modeling habits for the purposes of clarity, communication and reliability. 'Best practices' of spreadsheet modeling is particularly appropriate when designing spreadsheet for other users (Ronen, Palley and Lucas, 1989). This will benefit not only the students but also colleagues, instructor or even a boss. An important element of good spreadsheet modeling is the documentation of spreadsheet model for the purpose of sharing them with others or communicating them in presentations and reports. The other important element is readability. Grading homework assignments and exams can be a very time-consuming chore if students are permitted to construct their models in any form. Spreadsheet is inherently free-form and imposes no particular structure on the way problems may be modeled (Conway and Ragsdale, 1997). Although model building is an art and comes only with practice (Mathur and Solow, 1994), there is also a place for a relatively structured approach so that students have a conceptual approach and design guidelines they can follow whilst they gain experience. The OR course therefore introduces a structured spreadsheet modeling methodology, along with the specific OR techniques and examples. The structured methodology aims to lead to better spreadsheet models and enhanced reliability. This methodology teaches students for example to have a clear, logical layout to the overall model; separate different sections of the model i.e. inputs, decision variables and outputs with clear headings; separate different parts of a model across multiple worksheets; make liberal use of range names, formatting features, labels, comments and text boxes. A clear overall layout is important as to what should go where. Students are urged to plan ahead, before diving in. And if the plan does not look good once they start filling in the spreadsheet they can immediately revise their plan. The separation of the inputs, outputs and the decision variables means that the underlying model becomes more independently manageable. The students are encouraged to use labels, cell comments, and text boxes in order to document the logic behind the models whenever it is appropriate. One short sentence can be all it takes to let the reader know how or why some things 
are done in a certain way. Other useful methodological and design principles are debated in Conway and Ragsdale (1997) and Mather (1999).

\subsection{User-friendliness}

As noted by Conway and Ragsdale (1997), apart from positional separation, the inputs, decision variables and outputs can be color coded to enhance user-friendliness. For example, all decision variables cells can be in a red border, all input cells in a blue border and shaded, and the target cell (output) in a double black border. Color coding helps to improve the clarity of the model. The student modeler as well as the user can see the logical flow of calculation dependency.

\section{Results of Practical Experience Using Spreadsheets}

\subsection{My experiences}

In order to be able to teach this course successfully, each student must have his or her own computer. The classroom used to teach this course must have a projector so that the computer images can be projected on a large screen. An OR course is usually packed with topics and introducing spreadsheets may cause apprehension amongst some instructors. This is a legitimate concern. When spreadsheet was introduced, some of the traditional OR topics such as transportation and assignment models, network models, forecasting, multi-criteria decision making, etc. were omitted. Teaching OR via spreadsheets takes away some of the time that can used to teach a new topic, but the few topics taught imparts valuable spreadsheet and modeling skills that students can appreciate, apply and take with them into their careers. Teaching a spreadsheet-based OR course is very time consuming. It takes considerably more time to prepare for classes. The spreadsheet model examples exhibited in class must work correctly, must be presented in a logical step-by-step manner, be well-documented and written clearly so that students can learn from them and subsequently apply them in homework problems. Grading homework and tests also takes a long time. Also, the instructor must be available to help students when they get stuck in doing their homework problems.

\subsection{Student evaluations and responses}

A survey was taken in the lecture of 52 students to gauge their satisfaction with the OR course and to collect information on abilities and attitudes in using the computer and spreadsheet. The course had been running for thirteen weeks and most of the material was covered. The questionnaire asked about the relevance of the course and the expected value in the students' future career. It also asked about the four learning methods used in the course: lectures, tutorials, spreadsheets and the textbook. The students were asked to state how interesting and useful they found each of the learning methods. A five-point Likert scale was used which ranged from very unfavorable (score 1) through to very favorable (score 5). The results of these responses are presented in Table 1 and 2.

Table 1 presents the results of the relevance and expected value of the course in the students' future career. The results show that all students generally agree that the course was relevant and will add value to their future career. $76 \%$ of course feedback respondents believed that the course was relevant or very relevant and about $70 \%$ found the value added to their future career to be high or very high. The general conclusion is that the course is well received and students recognize its contribution to their collection of tools for OR.

The students' perception of the interest level and the usefulness of the different learning method are presented in Table 2. The students' perception in this analysis appears to be relatively insensitive to the different course delivery modes. It may be that students' responses are affected by factors beyond the scope of the student satisfaction questionnaire. Also, at the similar point of time, the departments in the Faculty of Economics and Administration evaluate teaching performance across all courses using students' ratings. So, the students end up filling so many questionnaires that many just tick boxes without reading questions. This may explain the ratings given to the question on the level of interest and usefulness of the different learning methods. Within this limitation, the students were generally quite satisfied with the course and its design. The use of spreadsheet to teach OR has received positive feedback. The design of the course by integrating spreadsheet appears to have been regarded as making the course interesting and useful to help learning of the OR techniques.

Representative comments of the student who took Introduction to Operations Research regarding the use of spreadsheet is given below, followed by the rating the comment was given:

'Excel is very complicated and easy to make mistakes.' (2- unfavorable)

'I don't have enough skill and knowledge to use spreadsheet. Special lectures on Excel is needed.' (2 - unfavorable)

'We need to be taught more basic spreadsheet to enhance understanding. But Excel is very useful in solving problems.' (3- average)

'The use of spreadsheet made topics more clearer and saved time.' ( 3 - neutral) 
'It is very practical because problems can be easily solved. There is a lot of spreadsheet usage in the working world and taking this course will help the students in future.' (4 - favorable)

'Very interesting. We learnt how to use Excel and how to model a problem using Excel. We learnt how to separate the different parts of the model and know which formula goes in which cell.' (4 - favorable)

'Very useful in solving various problems. And the results generated by spreadsheet is quite easy to understand.' (5 very favorable)

'Spreadsheet is interesting because we can apply the knowledge that we have learned in the real working world.' (5-very favorable)

'The usage of spreadsheet to solve problems in OR was interesting and relevant.' ( 5 - very favorable)

The feedback provided an indication that the majority students found the use of spreadsheet for modeling interesting, practical and useful. There were a handful of students who requested for more training in Excel. The review of basic spreadsheet skills given in the lecture was found to be insufficient to bring this small group of students to the skill level of their peers who have previous or concurrent training. The remedy to this problem is discussed in the following paragraphs. Nonetheless, the general conclusion is the use of spreadsheet is an effective way to encourage the development of modeling skills in students taking an introductory OR course.

The questionnaire also asked the students to assess their attitude and ability to use computers in general and spreadsheet in particular. The computer and spreadsheet ability was a subjective self-assessment. The measure of attitude and ability was again the five-point Likert $(1-$ dislike computer/poor, $5=$ like computer/excellent). Students' attitude towards using computers and spreadsheets is given in Table 3 while students' perception of their ability to use computers and spreadsheets is presented in Table 4.

The students generally possess a positive attitude towards using computers and spreadsheets. The results were split between students who have previous or concurrent computer and spreadsheet exposure and those who had not. There is a difference in attitude between the groups of students who have previous or concurrent exposure to computers compared with those who had not. The students that have previous or concurrent exposure to computers possess a higher attitude level towards using computers than those who had no previous exposure. One obvious reason why the non-exposed group favour less the use of computers and spreadsheet is because they have difficulty in using them. The problem can be overcome by offering computer and spreadsheet classes to all students before the OR course commences. Alternatively, these students can be identified later and remedial teaching provided.

Generally, the students perceive themselves to be quite able to use computers and spreadsheets. Since data on students' perceived ability was not collected at the start of the course, the changes in ability between the start and end of the year could not be measured. However, it is comforting to note that all of them are starting to acquire the necessary computer and spreadsheet skills needed in the workplace. Again the results were analysed according to students' level of computer and spreadsheet exposure. As with the students' attitude, the students who have computer and spreadsheet exposure display a different result to the students who did not have computer exposure. The self-measured ability of the group that had exposure to computers is significantly higher than the group who has no exposure. Another general conclusion that can be drawn from this analysis is that there is a positive relationship between the attitude of the students and their perceived ability to use computers and spreadsheets.

\section{Conclusion}

There are many compelling reasons for integrating computers and spreadsheet in the OR course, especially the desire to prepare student for the 'real world'. By using spreadsheet we are developing students' skills with a standard tool of today's business world and simultaneously opening their eyes to how a variety of quantitative OR model can be applied with popular commercial software packages being used in the business world. The ability to do 'what if' analysis, to make tables, graphs and charts to show the analysis of the results, and in addition the ability to do OR modeling, all gives students a competitive advantage when job hunting.

Grossman (2001) encouraged OR instructors to consider the needs and interests of the students when designing and delivering the OR course. We must understand the mindset of the students and give them a foundation of effective, efficient spreadsheet modeling with a few basic OR techniques that they can appreciate and take with them into their future career (Grossman, 2003). The students response in this OR course indicate that they know that they need spreadsheet and modeling skills to succeed in their jobs. This course delivers these in abundance.

This paper has described and explained one course's approach for spreadsheet-based OR teaching. It is hoped that the approach is found useful to other instructors, and the paper stimulates further interest in the use of this powerful software for OR teaching and use. 


\section{References}

Balakrishnan, N., Render, B., \& Stair, R.M. (2007). Managerial Decision Modeling with Spreadsheets. (2 ${ }^{\text {nd }}$ ed.). Prentice Hall: New Jersey.

Bodily, S.E. (1986). Spreadsheet Modeling as a Stepping Stone. Interfaces, 16(5), 34-52.

Cochran, J.J. (2000). Introductory Business OR Cases: Successful Use of Cases in Introductory Undergraduate Business College Operational Research Courses. Journal of the Operational Research Society, 51 (12), 1378-1385.

Conway, D.G. \& Ragsdale, C.T. (1997). Modeling Optimization Problems in the Unstructured World of Spreadsheets. Omega, 25 (3), 313-322.

DaCosta. J. (1979). A Sample Survey of Corporate Operations Research. Interfaces, 9 (4), 102-110.

Erkut, E. (1998). How to "Excel" in Teaching Management Science. OR/MS Today, 25(5), 40-43.

Fortuin, L. \& Zijlstra. M. (2000). Operational Research in Practice: Consultancy in Industry Revisited. European Journal of Operational Research, 120, 1-13.

Grossman, T.A. (2001). Causes of Decline of the Business School Management Science Courses. INFORMS Transactions on Education, 1 (2), 51-61.

Grossman, T.A. (2003). Spreadsheet Modeling is a Strategic Opportunity. OR/MS Today, 30 (5), 12-14.

Grossman, T.A. (2006). The Spreadsheet Analytic Value Chain. OR/MS Today, 33(4).

Hesse, R., Scerno, D.H. (2009). How Electronic Spreadsheet Changed the World. Interfaces 39(2), 159-167.

LeBlanc, L. \& Grossman, T.A. (2008). The Use of Spreadsheet Software in the Application of Management Science and Operations Research. Interfaces, 38(4), 225-227.

Leon, L., Przasnyski, Z. \& K.C. Seal. (1996). Spreadsheets and OR/MS Models: An End-User Perspective. Interfaces, 26 (2), 92-104.

Mather, D. (1999). A Framework for Building Spreadsheet Based Decision Models. Journal of the Operational Research Society, 50, 70-74.

Mathur, K. \& Solow. D. (1994). Management Science: The Art of Decision Making. Prentice-Hall, New Jersey.

Morris, W.T. (1967). On the Art of Modeling. Management Science, 13 (12), B707-717.

Pidd, M. (1999). Just Modeling Through: A Rough Guide to Modeling. Interfaces, 29 (2), 118-132.

Powell, S.G. (1997a). Leading the Spreadsheet Revolution. OR/MS Today, 24, 6: 8-9.

Powell, S.G. (1997b). The Teachers' Forum: From Intelligent Consumer to Active Modeler, Two MBA Success Stories. Interfaces, 27 (3), 88-98.

Powell, S.G. (1998). The Teachers' Forum: Requiem for the Management Science Course? Interfaces, 28 (2), 111-117.

Ronen, B., Palley, M.A. \& Lucas H.C., Jr. (1989). Spreadsheet Analysis and Design. Communication of the ACM, 32, 84-93.

Savage, S. (1997). Weighting the PROS and CONS of Decision Technology in Spreadsheets. OR/MS Today, 24 (1), $42-45$.

Thiriez, H. (2001). Improved OR Education Through the Use of Spreadsheet Models. European Journal of Operational Research, 135, 461-476.

Vazsonyi, A. (1993). Where We Ought to be Going: The Potential of Spreadsheets. Interfaces, 23 (5), 26-39.

Winston, W.L. (1996). The Teachers' Forum: Management Science with Spreadsheets for MBAs at Indiana University. Interfaces, 26 (2), 105-111.

Winston, W. L., \& Albright, S.C. (2001). Practical Management Science. $\left(2^{\text {nd }}\right.$ ed.). Duxbury, USA.

Table 1. The relevance and expected value of course in future career

\begin{tabular}{|l|l|l|}
\hline & Mean & Standard Deviation \\
\hline Relevance & 3.846 & 0.538 \\
\hline Expected value & 3.778 & 0.637 \\
\hline
\end{tabular}


Table 2. Students' perception of the interest level and the usefulness of the different learning methods

\begin{tabular}{|l|l|l|}
\hline Learning methods & Mean & Standard Deviation \\
\hline Lectures & 3.692 & 0.579 \\
\hline Tutorials & 3.635 & 0.595 \\
\hline Textbook & 3.730 & 0.528 \\
\hline Spreadsheet & 3.712 & 0.957 \\
\hline
\end{tabular}

Table 3. Attitude to using computers and spreadsheets

\begin{tabular}{|l|l|l|l|}
\hline Computer \& Spreadsheet Attitude & N & Mean & $\begin{array}{l}\text { Standard } \\
\text { Deviation }\end{array}$ \\
\hline All students & 52 & 3.750 & 0.764 \\
\hline $\begin{array}{l}\text { Students with previous or concurrent } \\
\text { exposure to computers and spreadsheets }\end{array}$ & 41 & 3.786 & 0.782 \\
\hline $\begin{array}{l}\text { Students with no exposure to computers and } \\
\text { spreadsheets }\end{array}$ & 11 & 3.363 & 0.674 \\
\hline
\end{tabular}

Table 4. Self-measured computer and spreadsheet ability

\begin{tabular}{|l|l|l|l|}
\hline Computer \& Spreadsheet Ability & N & Mean & $\begin{array}{l}\text { Standard } \\
\text { Deviation }\end{array}$ \\
\hline All students & 52 & 3.654 & 0.738 \\
\hline $\begin{array}{l}\text { Students with previous or concurrent } \\
\text { exposure to computers and spreadsheets }\end{array}$ & 41 & 3.738 & 0.734 \\
\hline $\begin{array}{l}\text { Students with no exposure to computers and } \\
\text { spreadsheets }\end{array}$ & 11 & 3.273 & 0.647 \\
\hline
\end{tabular}

1. Problem Formulation: Observe system and summarize problem situation

Identify problem for analysis

Define problem

2. Model Development: $\quad$ Construct a mathematical model

Find preferred solution

Verify model and test performance

Analyse sensitivity of solution

3. Implementation: Generate report and demonstrate model

Plan implementation

Establish control over solution

Implement solution

Follow up on solution use

Figure 1. Summary of the main phases of the OR methodology 